\title{
Numerical modelling of wave transformation over submerged breakwaters using Boussinesq-type models
}

\author{
Roshan Suminda Ranasinghe* \\ Northshore College of Business and Technology, No. 141, Church Road, Colombo 15.
}

Revised: 11 December 2017; Accepted: 18 January 2018

\begin{abstract}
Predictive skills of two numerical models, which are developed using two widely-recognised Boussinesq-type equations were further investigated in modelling evolution of water waves propagating over submerged breakwaters and the results were compared. These models are often used for practical applications due to their capabilities of simulating complex hydrodynamic characteristics in nearshore region. However, both models are found to be vulnerable to numerical instabilities when simulating wave propagation over submerged breakwaters particularly with small freeboards and steep face slopes. An artificial energy dissipation term was successfully introduced locally into one of the Boussinesq-type models to overcome unrealistic flow patterns that lead to these numerical instabilities near submerged breakwaters and the modified model was verified using a new set of wave flume data.
\end{abstract}

Keywords: Abrupt depth configurations, Boussinesq-type equations, energy dissipation, submerged breakwaters, turbulent kinetic energy model.

\section{INTRODUCTION}

Due to a number of aesthetic and environmental advantages, submerged breakwaters became popular as a shore protection structure and started drawing worldwide attention during the last few decades. However, the lack of understanding of the evolution of waves and currents, and the resulting morphological changes around submerged breakwaters sacrifice all the potential advantages offered by them. Due to the large number of structural and environmental variables associated with the hydro-morphodynamics around submerged breakwaters, it is practically impossible to realise a complete understanding of hydro-morphodynamics in the vicinity of submerged breakwaters with physical model tests. Numerical modelling is the only feasible technique, which could address this knowledge gap (Ranasinghe et al., 2010).

In numerical modelling of waves and wave-induced currents around submerged breakwaters, there are many complex hydrodynamic characteristics to be dealt with. In order to simulate these complex hydrodynamic characteristics, a time-dependent, nonlinear dispersive wave model is the most straightforward approach. Hence, efforts have been made in this study to discuss the evolution of water waves and currents in the vicinity of submerged breakwaters using two widely-used Boussinesq-type equations, particularly in commercial applications (Madsen \& Sorensen, 1992; Nwogu, 1993).

Boussinesq-type equations have made remarkable development over the last couple of decades largely due to the critical steps provided by Madsen et al. (1991) and Nwogu (1993). Most of the subsequent theories, which were developed to extend the nonlinearity (Wei et al., 1995; Chen et al., 2003) and frequency dispersion properties (Madsen et al., 1996; Gobbi et al., 2000) were based on Madsen et al. (1991) and Nwogu (1993) platform equations. Equations by Madsen et al. (1991) were extended in Madsen and Sorensen (1992) to include terms proportional to bottom slope, which are essential for demonstrating shoaling characteristics of waves.

\footnotetext{
*r.s.ranasinghe@northshore.edu.lk; iD https://orcid.org/0000-0003-1168-0577
} 
Although there have been a number of studies investigating the evolution of waves and currents around submerged breakwaters, and the resulting morphological changes around them with linear models, very few studies have been conducted to investigate the evolution of waves and wave-induced nearshore currents around submerged breakwaters using Boussinesq-type models. Some exceptions are Johnson et al. (2005) and Johnson (2006) where a higher-order Boussinesq-type model was validated (Karambas \& Koutitas, 2002) with improved linear dispersion properties together with nonlinear long wave equations for porous media (Cruz et al., 1997). The studies compared the computational results (both $1 \mathrm{DH}$ and 2DH) with experimental measurements provided by Vidal et al. (2002), Gironella and Sanchez-Arcilla (1999), and Zanuttigh and Lamberti (2003). Yet, there exist some ambiguities even on $1^{\text {st }}$ order quantities such as wave heights due to the inaccurate prediction of wave breaking and breaking induced energy dissipation (not only limited to prediction of wave evolution around submerged structures). At the same time, it should be noted that the reason for the lack of literature on modelling of nearshore hydrodynamics around submerged breakwaters could be due to the fact that most of the Boussinesq-type models fail to simulate realistic flow patterns over steep bottom slopes and abrupt depth configurations.

The aims of this study were to discuss potential numerical instabilities associated with Boussinesqtype models (they are extremely good for practical applications on mildly sloping beaches but inherently inapplicable to steep bottom configurations) in simulating the hydrodynamics around submerged breakwaters (particularly with steep face slopes), introduce a possible technique to improve their stability to make the two models still applicable on such local bottom configurations, and to validate a model developed based on Nwogu (1993) Boussinesq-type equations for 1DH wave propagation. MIKE21 BW commercial software was used to represent Madsen and Sorensen (1992) Boussinesq-type equations (no access to the source code); therefore no changes could be made to the source code to improve the stability. Hence, the results are only limited to Nwogu (1993) Boussinesq-type model after the improvements.

\section{METHODOLOGY}

In this study, numerical simulations were performed to investigate nonlinear wave transformation over submerged breakwaters with a model developed based on Nwogu (1993) Boussinesq-type equations and with MIKE21 BW model (Madsen \& Sorensen, 1992) in 1DH.
Although a number of upgrades have been presented over the past two decades, still Nwogu (1993) and Madsen and Sorensen (1992) Boussineq-type equations are preferred and used for commercial purposes in nearshore wavecurrent modelling due to simplicity and stability of these models on mildly sloping beaches. The models developed with higher order, nonlinear, dispersive Boussinesq-type equations or Navier-Stokes equations are difficult to be deployed in practical applications due to stability issues and very high computational time. A short description of the governing equations and different sub-models used in the two models are presented below.

\section{Model based on Nwogu (1993) Boussinesq-type equations (model 1)}

\section{Governing equations}

Nwogu (1993) Boussinesq-type equations are solved in the time domain using a third-order Adams-Bashforth predictor step and a fourth-order Adams-Moulton corrector step.

In one horizontal dimension, the governing equations read as:

Continuity equation:

$$
\begin{aligned}
\eta_{t}+\left[(h+\eta) u_{\alpha}\right]_{x} & +\left\{\left(\frac{z_{\alpha}^{2}}{2}-\frac{h^{2}}{6}\right) h u_{\alpha x x}\right. \\
& \left.+\left(z_{\alpha}+\frac{h}{2}\right) h\left(h u_{\alpha}\right)_{x x}\right\}_{x}=0
\end{aligned}
$$

Momentum conservation equation:

$$
\begin{aligned}
u_{\alpha t}+g \eta_{x}+u_{\alpha} u_{\alpha x}+\frac{z_{\alpha}^{2}}{2} u_{\alpha x x t} & +z_{\alpha}\left(h u_{\alpha}\right)_{x x t} \\
& +F_{f N}-R_{b N}=0
\end{aligned}
$$

where, $\eta$ is the free water surface elevation, $h$ is the still water depth, $z_{\alpha}$ is the reference water depth, and $u_{\alpha}$ is the velocity at reference water depth along the $x$ axis.

Two additional terms are introduced into the momentum conservation equation to simulate the dissipation of wave energy due to bottom friction and wave breaking, which are represented by $F_{f N}$ and $R_{b N}$. 


$$
F_{f N}=\frac{1}{(h+\eta)} f_{w} u_{b}\left|u_{b}\right|
$$

where, $f_{w}$ is the wave friction factor and $u_{b}$ is the nearbottom wave orbital velocity along the $x$ axis.

Following Kennedy et al. (2000), a simple eddy viscosity type of formulation is adopted to simulate energy dissipation due to wave breaking (by introducing momentum-mixing term into momentum conservation equation in $x$ direction);

$$
R_{b N}=\frac{1}{(h+\eta)}\left\{v_{t}\left[(h+\eta) u_{\alpha}\right]_{x}\right\}_{x}
$$

The rate of wave energy dissipation is expected to be governed by the magnitude of the eddy viscosity, $v_{t}$, which is related to the turbulent kinetic energy, $k$, and a turbulent length scale, $l_{t}$. The turbulent kinetic energy is determined from a semi-empirical transport equation with a source term for turbulent kinetic energy production by wave breaking, i.e., one equation turbulence closure model (Nwogu, 1996):

$$
\begin{aligned}
& k_{t}+u_{\mathrm{s}} . k_{x}=\left(\frac{v_{t}}{\sigma_{k}} k\right)_{x x}+A v_{t}\left[\left(\frac{\partial u}{\partial z}\right)^{2}\right]_{z=\eta}-C_{D} \frac{k^{3 / 2}}{l_{t}} \\
& v_{t}=\sqrt{k} l_{t}
\end{aligned}
$$

where, $u_{s}$ is the free surface wave orbital velocity along the $x$ axis.

Parameter $A$ is introduced to ensure that the turbulence is produced only when the horizontal velocity at a reference water depth, $u_{\alpha}$, exceeds a threshold velocity (i.e $u_{\alpha} / C>0.40$ ). The length scale, $l_{t}$ is set to be half of the incident wave height $\left(l_{t}=0.0195 \mathrm{~m}\right)$, while the empirical coefficients $C_{D}$ and $\sigma_{k}$ for this submodel are set to be 0.08 and 1 , respectively.

To trigger the turbulent kinetic energy equation, an initial estimate of eddy viscosity, $\boldsymbol{v}_{t}$ is necessary. This is obtained by assuming a local balance between the production and dissipation of turbulent kinetic energy as follows:

$$
v_{t}=\frac{l_{t}^{2}}{\sqrt{C_{D}}}\left(\frac{\partial u}{\partial z}\right)_{z=\eta}
$$

\section{Offshore open boundary}

As there is significant wave reflection from submerged breakwaters, it is essential to absorb the waves, which propagate back to wave incident boundary to prevent build-up of wave energy inside the computational domain. This is achieved with the line boundary method proposed by Ishii et al. (1994). In this method, the neighbouring grid points are divided into two types according to their position with respect to the line boundary. Both incident and outgoing waves exist inside the line boundary, whereas only outgoing waves exist outside the line boundary. To completely dissipate the energy of outgoing waves a sponge layer with an adequate width is provided outside the line boundary.

\section{Moving shoreline boundary}

To tackle the moving shoreline problem in Boussinesqtype models, Madsen et al. (1997) extended the computational domain artificially by replacing the solid beach by a permeable beach characterised by a very small porosity. Instead of tracking the moving boundary during wave runup/rundown on the beach, the study treated the entire computational domain as an active fluid domain. In the model, each vertical cross-section is assumed to be comprised of a physical regime with clear water on top of the artificial porous flow regime. This moving shoreline boundary technique is employed in model 1 to be consistent with model 2 .

\section{MIKE21 BW model (model 2)}

MIKE21 BW model solves the enhanced Boussinesqtype equations formulated by Madsen and Sorensen (1992), which are expressed in one or two horizontal dimensions in terms of the free surface elevation $\eta$, and the depth-integrated velocity components $P$ and $Q$ along the $x$ and $y$ axes, respectively. Here also the governing equations are solved in the time domain using a thirdorder Adams-Bashforth predictor step and a fourth-order Adams-Moulton corrector step in 1DH.

Ignoring porous damping terms, the governing equations in MIKE21 BW model in one horizontal dimension read as:

Continuity equation:

$\eta_{t}+P_{x}=0$ 
Momentum conservation equation:

$$
\begin{gathered}
P_{t}+g d \eta_{x}+\left(\frac{P^{2}}{d}\right)_{x}-\left(B+\frac{1}{3}\right) h^{2} P_{x x t}-\frac{1}{3} h h_{x} P_{x t} \\
-B g d^{2} w_{x}+F_{f M S}+R_{b M S}=0
\end{gathered}
$$

$w=\left(h \eta_{x}\right)_{x}$

where $d$ is the total water depth, which is given by $(h+\eta)$. The auxiliary variable $w$ is introduced to handle the higher order spatial derivatives (particularly $\eta_{x x x}$ term) in Madsen and Sorensen (1992) equations. The dispersion coefficient $B$ is set to have the value $1 / 15$, which provides linear dispersion characteristics corresponding to Pade $[1,1]$ expansion of Stokes linear dispersion relation [identical to the dispersion characteristics of Nwogu (1993) Boussinesq-type equations].

Wave energy dissipation due to bottom friction and respectively wave breaking are represented by $F_{f M S}$ and $R_{b M S}$, respectively.

$$
F_{f M S}=\frac{g}{h^{2} C z^{2}} P|P|
$$

where, $C z$ is the Chezy resistance number.

The term denoted by $R_{b M S}$ accounts for the excess momentum flux due to the presence of surface roller and is defined by:

$R_{b M S}=\left[\frac{\delta}{1-\delta / d}\left(C-\frac{P}{d}\right)^{2}\right]_{x}$
Here $\delta=\delta(x, t)$ is the thickness of the surface roller and $C$ is the roller celerity. The temporal and spatial evolution of surface rollers is determined based on the heuristic geometrical approach as described in Shaffer et al. (1993).

Internal wave generation is implemented using the open boundary technique proposed by Larsen and Dancy (1983) together with a sponge layer placed along the region, where outgoing waves exist.

\section{Wave flume experiments}

A series of laboratory experiments was conducted in the wave-current flume $(35.0 \mathrm{~m}$ long, $0.6 \mathrm{~m}$ wide and $1.0 \mathrm{~m}$ deep) at the University of Tokyo to obtain data to investigate the predictive skills of the two numerical models. Submerged breakwater models were made of solid concrete blocks with side slopes of 1:1 and a crown width of $0.3 \mathrm{~m}$, and were placed $2.0 \mathrm{~m}$ offshore from the still water shoreline. Two datasets (case SB1 and SB2) are presented in this paper and layout of the experimental and computational domains are shown in Figure 1. In both test cases water level fluctuations were recorded at 26 locations $(3.45,3.25,3.05,2.85,2.65,2.45,2.35$, $2.25,2.20,2.15,2.10,2.05,2.00,1.95,1.90,1.85,1.80$, $1.75,1.65,1.55,1.45,1.25,1.05,0.85,0.65,0.45 \mathrm{~m}$ from still water shoreline). However, water level fluctuation associated with case SB2 at wave gauge \#10 was not recorded due to wetting and drying coexisting field. Wave transformation over both submerged breakwaters was tested under monochromatic waves with an offshore wave height of $0.039 \mathrm{~m}$ and a wave period of $1.0 \mathrm{~s}$ while maintaining a water depth of $0.3 \mathrm{~m}$ at the wave paddle. The freeboards (i.e. the distance between crown level of the submerged breakwater and still water level) were set at $0.028 \mathrm{~m}$ and $0.01 \mathrm{~m}$ for test case SB1 and SB2, respectively.

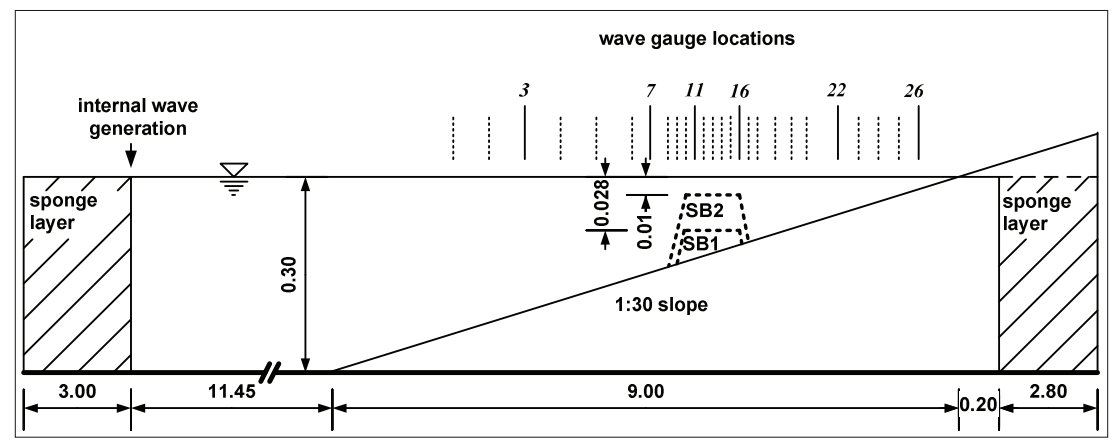

Figure 1: Layout of the experimental setup and computational domain

Note: The layout was not drawn to scale. All dimensions are in metres 


\section{RESULTS AND DISCUSSION}

In practice, offshore breakwaters are constructed with face slopes $1: 1,1: 1.33,1: 1.5$ or $1: 2$ depending on the type of armour units placed on the surface. The selection of the face slope will usually be dependent on the structural stability considerations and construction costs. For submerged breakwaters, the face slope can be maintained even at around $1: 5$ or $1: 10$ (in a very rare case), to enforce extra wave damping by porous resistance, bottom friction and wave breaking (simultaneously giving attention to possible wave shoaling when introducing mild face slopes particularly at the offshore end). Therefore, in comparison with the bottom slope of a natural beach (1:50 1:200), the face slope of a submerged breakwater would be considerably steep; hence evolution of hydrodynamic conditions near this interface will be substantially different.

Both Nwogu (1993) and Madsen and Sorensen (1992) Boussinesq-type equations are derived for water waves propagating over slowly varying bathymetries. A nearshore bathymetry with a submerged structure with steep face slopes would represent an abruptly changing bottom configuration and the validity of these equations were tested for such local change of depth in the present study. Model 1 and model 2 were setup according to the layout presented in Figure 1.

\section{Submerged breakwater with large freeboard}

\section{Model 1 results associated with case SB1}

The distribution of computed wave height and mean water level associated with case SB1 are presented in Figures $2 \mathrm{a}$ and $2 \mathrm{~b}$, respectively and are compared with the measurements. In this case it was guaranteed that the wave trough would not touch the crown of the submerged breakwater at any stage during the simulation period, which was also verified from the observations made during the physical model test.

The results demonstrate a fairly good agreement with the measurements except in the region shoreward of submerged breakwater, where an underestimation of wave heights is observed. In addition, model 1 is found to reproduce the partial wave reflection at the offshore face of submerged breakwater and the energy dissipation over it with a reasonable accuracy. However, a peculiar behaviour is noticeable at the boundary between crown and offshore face of the structure, particularly in the mean water level distribution. The sharp 'spike' observed in wave set-down is peculiar, although there exists an abrupt change of depth at this boundary.

\section{Model 2 results associated with case SB1}

The distribution of computed wave height and mean water level associated with case SB1 are depicted in

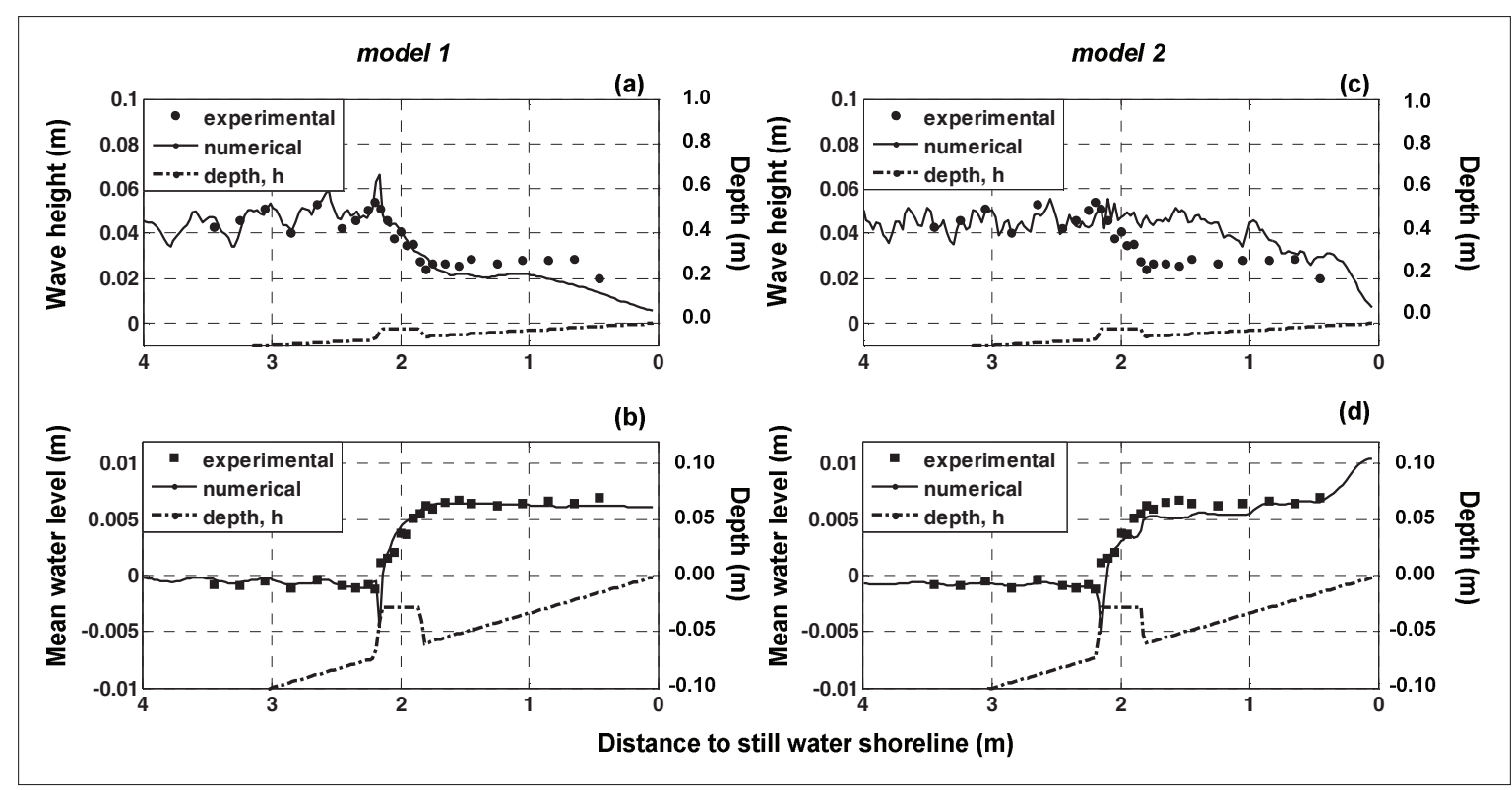

Figure 2: Comparison of distribution of wave height and mean water level simulated using model 1 (a,b) and model 2 (c,d) with observations associated with case SB1 
Figures $2 \mathrm{c}$ and $2 \mathrm{~d}$, respectively. In contrast to model 1 , model 2 simulation results deviate substantially from the measurements particularly in wave height distribution. However, similar to model 1 , model 2 is found to reproduce the partial wave reflection at the offshore face of the submerged breakwater. Interestingly, the peculiar 'spike' in wave set-down can also be observed in mean water level distribution at the same location where it is identified in model 1 results.

\section{Submerged breakwater with small freeboard}

Another set of simulations was performed to obtain the wave transformation over a submerged breakwater with a relatively small freeboard. In this case, the crown of the submerged breakwater was set to be subjected to wetting and drying coexisting field. In model 1, the possible discontinuity at this region is overcome by introducing a porous medium used in the moving shoreline technique of Madsen et al. (1997). Considering the bed as permeable with a finite porosity, the model does not require any special treatment at regions on submerged breakwater, which are subjected to wetting and drying coexisting field. The numerical values of model parameters are kept the same as used in case SB1 simulations.

During the simulations with case SB2, both models

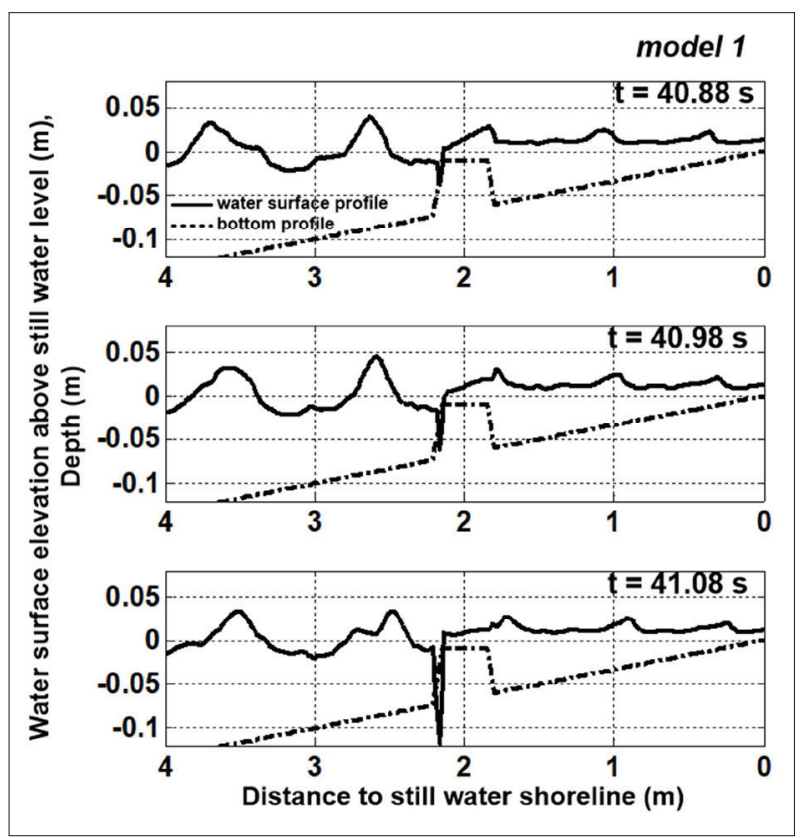

Figure 3: Instantaneous free water surface elevation simulated using model 1 at three successive time steps (just before instability) associated with case SB2 blew-up at a certain point after the commencement. The simulated instantaneous free water surface elevations associated with case SB2 at six successive time steps just before instability are depicted in Figure 3 (for model 1) and Figure 4 (for model 2).

\section{Model 1 results associated with case $S B 2$}

Model 1 ran a longer time (40.08 seconds) than model 2 and the point of instability was consistent with the position of the spike observed in case SB1 simulations, as it could be clearly seen in Figure 3. In the simulation, the slot width (permeability parameter) was set at 0.006 to be consistent with case SB1. Stability could be attained by setting a larger value of slot width but that is simply due to the increase in resulting effective water depth (Madsen et al., 1997) at the submerged breakwater. Moreover, this would be inconsistent with the infinitesimal permeability of solid concrete models used as submerged breakwaters. Still such increase in slot width is not found to suppress the spike in wave set-down completely unless a value of the order of 0.1 is used.

\section{Model 2 results associated with case SB2}

Model 2 blew-up 23.84 seconds after the commencement of the simulation and the point of instability was slightly

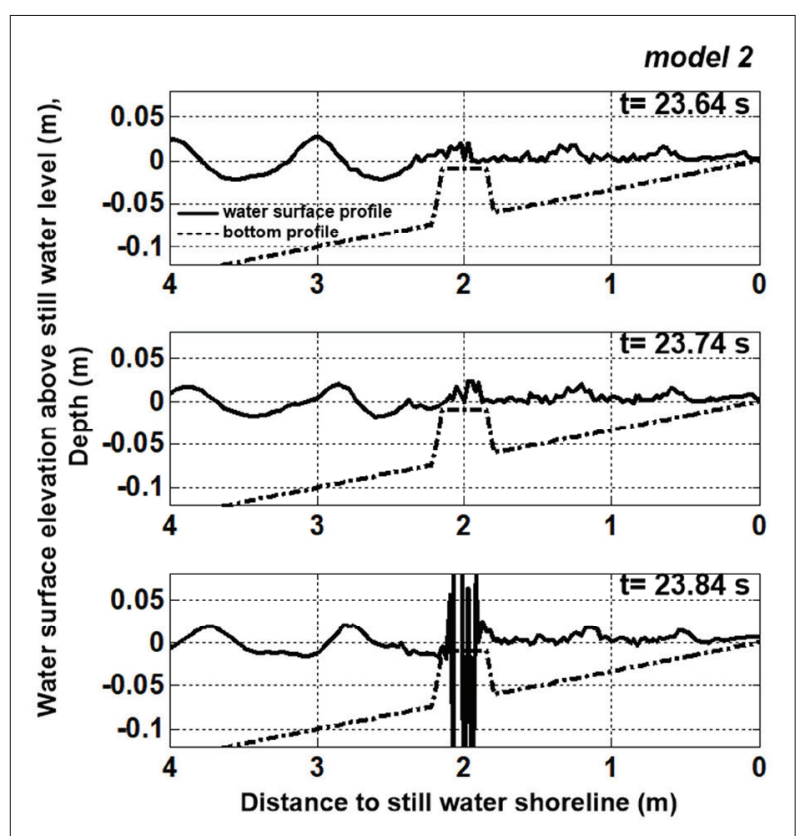

Figure 4: Instantaneous free water surface elevation simulated using model 2 at three successive time steps (just before instability) associated with case SB2 
inconsistent with that of model 1 simulations (Figure 4). This is mainly due to the difference in wave breaking induced energy dissipation sub-models used in the two models. It is well observed that the predicted wave set-up in the lee of submerged breakwater by model 2 is lower than that is predicted by model 1 . This low wave setup leads model 2 to be more vulnerable to instability, as total water depth $(h+\eta)$ could easily be close to zero or negative on the crown of breakwater.

\section{Energy dissipation at an abruptly changing bottom topography}

Nwogu (1993), and Madsen and Sorensen (1992) Boussinesq-type equations are essentially depthintegrated equations, which are developed to simulate nonlinear wave transformation over slowly varying bathymetries and do not include any formulation to account for the energy dissipation that would occur at an abruptly changing bottom. However, when performing numerical simulations to compute the wave transformation over submerged breakwaters with relatively steep face slopes, the physical mechanism of energy dissipation present around steep faces should be conclusively considered. It is worth investigating the flow characteristics in the vicinity of submerged breakwaters and how it could be replicated in the numerical model as well. In order to discuss this, there are essentially two cases, which should be clearly examined. First case: a submerged structure with a perfectly vertical face; second case: a submerged structure with a fairly steep face slope. Physically these two cases are slightly different and hydrodynamics around the face of the submerged structure will be slightly different as well. The clearest difference, which could be observed is on the size of vortices generated around the side face of the structure, hence the degree of energy dissipation due to turbulent eddies. Obviously more energy dissipation can be expected in the former compared to the latter. However, due to the finite difference scheme used with relatively coarse spatial grids, the bathymetry of the second case (with steep face slope) may virtually appear very close to that of the first case (with vertical face) in the numerical model. More focus is given to the offshore face of the submerged breakwater, as that end is found to be subjected to more energy dissipation in the physical model and vulnerable to instability in the numerical model.

\section{Modifications to governing equations}

It was essential to introduce a term into Boussinesq equations to replicate the energy dissipation near an abruptly changing bottom, as well as to suppress the 'spike' in wave set-down that leads to numerical instability in the model. Considering the similarities between the flow characteristics near steep face slope of a submerged structure and a rapidly varied flow in an open channel when there exist an abrupt drop in channel bed, the artificial energy dissipation term proposed by Ranasinghe et al. (2009) is incorporated into the momentum conservation equation (equation 2) of Nwogu (1993) Boussinesq-type model. Such energy dissipation mechanism is also found in pipe systems, when there exists a sudden enlargement of pipe diameter.

Numerical simulation results confirm that the spike in wave set-down is due to the advection term $u_{\alpha} u_{\alpha x}$ in the momentum conservation equation. Hence, switching off the advection term $u_{\alpha} u_{\alpha x}$ from the momentum conservation equation when the flow velocity is offshoreward at the offshore edge of the crown of submerged breakwater, can also lead to the suppression of spike in wave set-down but such modification to the governing equations cannot be justified. Although Madsen and Sorensen (1992) Boussinesq-type equations are formulated in terms of volume fluxes $(P, Q)$, the vulnerability to numerical instability at steep face of a submerged breakwater would persist. This can be explained by expanding the advection terms in the momentum conservation equation.

In $x$-direction, advection term in $1 \mathrm{DH}$ is demonstrated by:

$\left[P^{2} /(h+\eta)\right]_{x}=(\bar{u} P)_{x}$

where $\bar{u}=P /(h+\eta)$ is the depth-averaged velocity in $x$-direction.

Further expansion of equation (13) yields to:

$(\bar{u} P)_{x}=\bar{u} P_{x}+P \bar{u}_{x}$

in which the second term in right-hand side of equation (14) will be equivalent to the advection term $u_{\alpha} u_{\alpha x}$ in Nwogu (1993) momentum conservation equation.

The artificial dissipation term is switched on during the computations only when the flow is offshoreward at offshore face and when the flow is onshoreward at onshore face of submerged breakwater. Nevertheless, the dissipation of energy at the onshore face is relatively minor compared to that at the offshore face of the submerged breakwater. At the offshore face, energy dissipation occurs under wave trough and the small total water depth over the submerged breakwater results in a relatively larger spatial gradient of velocity. Conversely, 
energy dissipation occurs under wave crest at the onshore face of the submerged breakwater. However, at this end wave energy is dissipated rapidly over the submerged breakwater by wave breaking and this leads to a rise in mean water level. Under such conditions, energy dissipation at the onshore face of the submerged breakwater is found to be negligible due to relatively larger total water depths. Furthermore, the wave breaking induced energy dissipation is more dominant than the energy dissipation due to sudden change of depth. A number of trial simulations revealed that the introduction of artificial dissipation term at the onshore face of submerged breakwater has very little effect on the total dissipation of energy over the submerged breakwater and potential numerical instability.

The instantaneous free water surface elevations simulated using model 1 at three successive time steps associated with case SB2 (having introduced the artificial energy dissipation at the offshore face of submerged breakwater only) are depicted in Figure 5. In the previous simulation run with case SB2 (without the artificial dissipation term), model 1 blew up 41.08 seconds after the commencement. The introduction of artificial energy dissipation term not only eliminated the sharp spike in wave profiles at the offshore end of the crown of submerged breakwater, but also resulted stable computation.

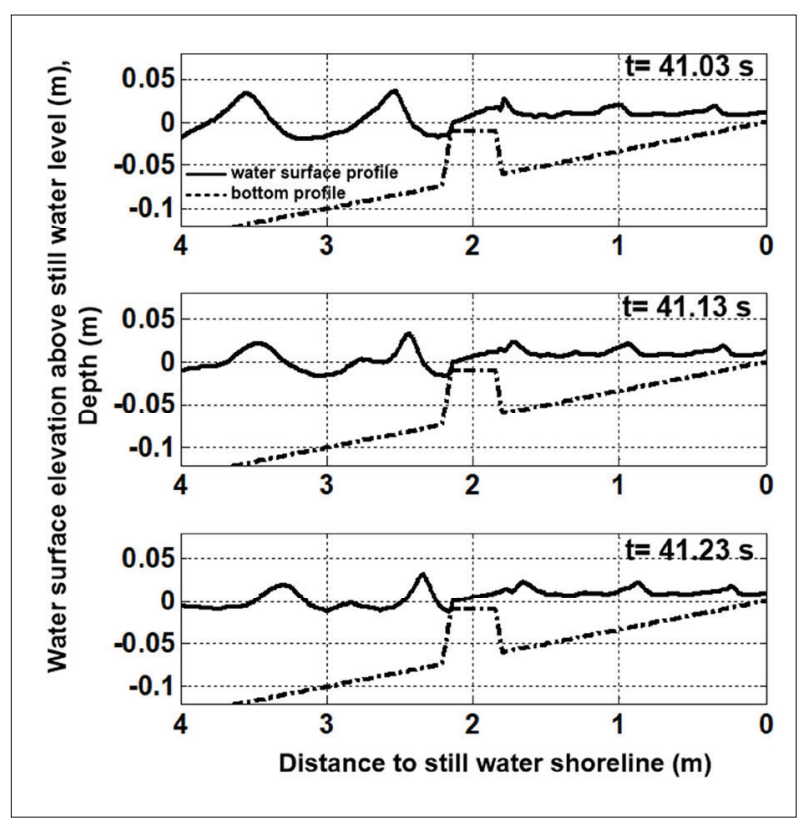

Figure 5: Instantaneous free water surface elevations simulated using model 1 at three successive time steps (with stable computation) associated with case SB2

The distribution of wave height and mean water level simulated using model 1 associated with case SB1 is depicted in Figures 6a and 6b, respectively and are

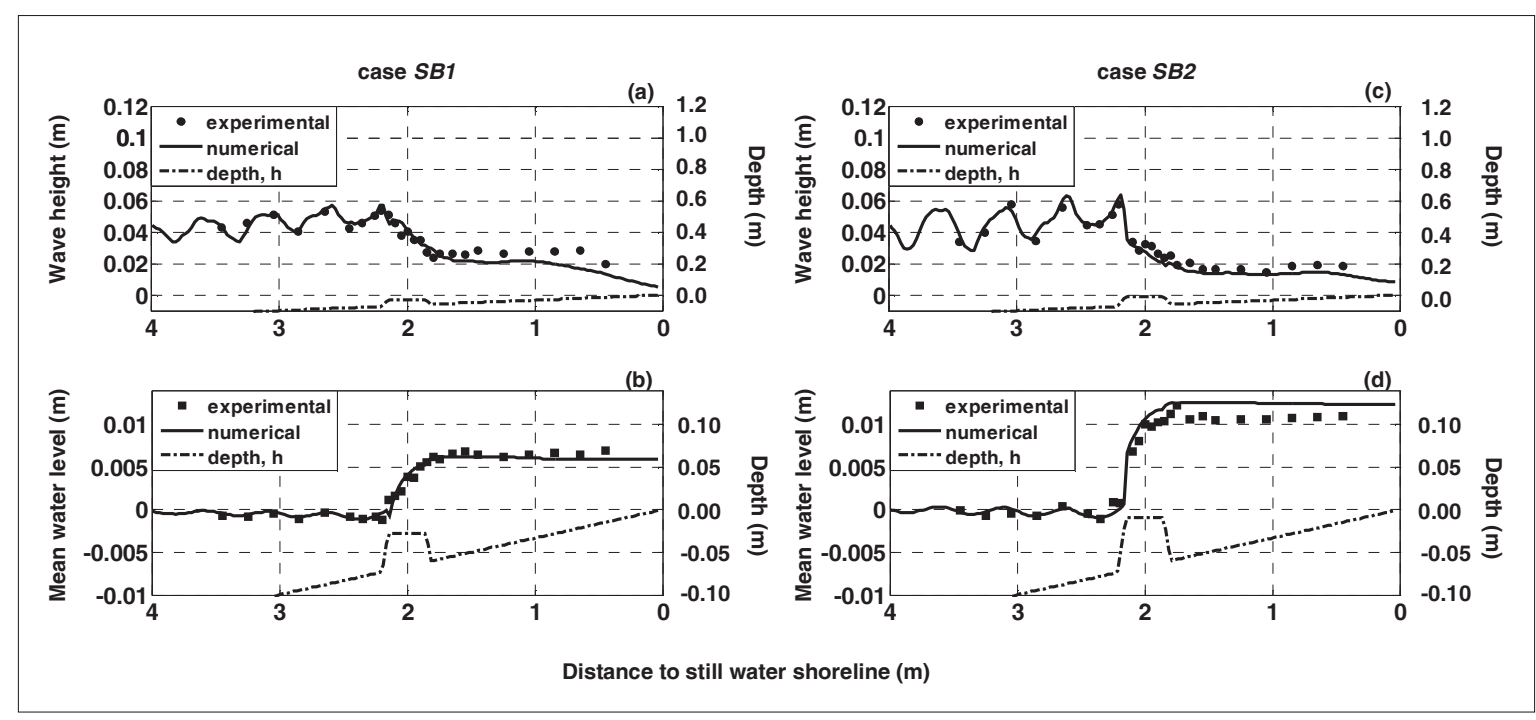

Figure 6: Comparison of distribution of wave height and mean water level simulated using model 1 with measurements associated with case SB1 (a,b) and SB2 (c,d) 
compared with the measurements. The sharp spike observed in wave set-down in the previous simulation (Figure 2b) is now suppressed with the introduction of artificial energy dissipation term. For this case, the dissipation term is switched on only at two grid points along the offshore face of the submerged breakwater. The simulated wave heights and mean water levels associated with case SB1 agree fairly well with the experimental data. The major discrepancy is in the region shoreward of submerged breakwater, where an underestimation of wave heights is observed. Otherwise, the energy dissipation of waves and the rise in mean water level over submerged breakwater are well predicted by the model. The time series of free water surface fluctuations at gauge positions \# 03, 07, 11, 16, 22 and 26 associated with case SB1 is shown in Figure 7 for further verification. Apart from the slight over-damping of waves in the lee of submerged breakwater, the simulated wave profiles show excellent agreement with the observations reproducing the generation of higher harmonics as well.

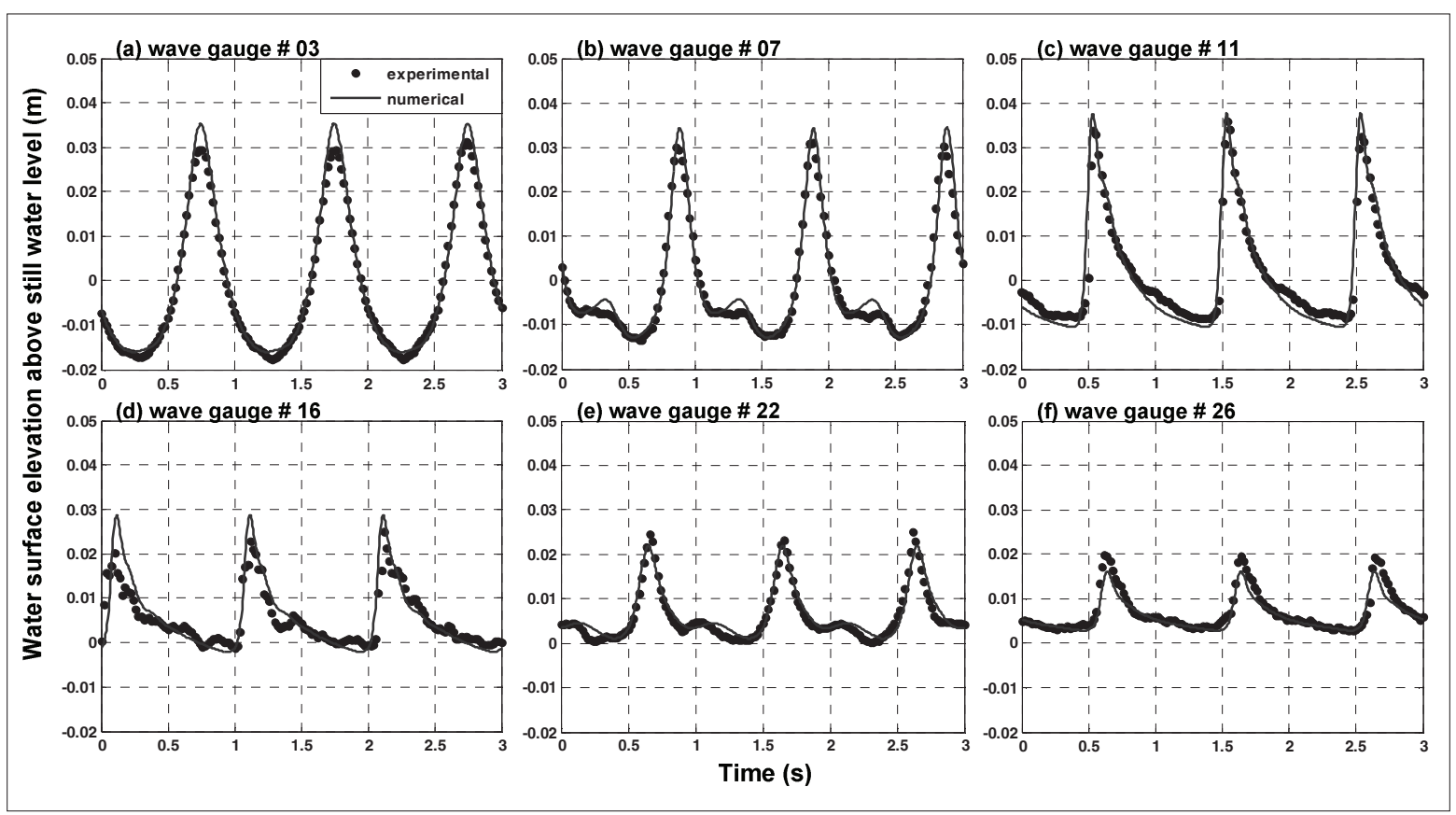

Figure 7: Comparison of instantaneous free water surface elevations simulated using model 1 with measurements at six different wave gauge positions associated with case SB1

The distribution of wave height and mean water level simulated using model 1 associated with case SB2 are depicted in Figures $6 \mathrm{c}$ and $6 \mathrm{~d}$, respectively and are compared with the measurements. The model is found to reproduce the partial wave reflection at the offshore face of submerged breakwater and the energy dissipation over the offshore half of it with a reasonable accuracy. The slight over-dissipation of wave energy observed over the onshore half of the submerged breakwater is found to be the reason for the overestimation of mean water level in the lee of submerged breakwater. In both the cases, model 1 is found to reproduce the wave recovery after the first breaking over the submerged breakwater and the second breaking near shoreline.
The time series of free water surface fluctuations at gauge positions \# 03, 07, 11, 16, 22 and 26 associated with case SB2 is illustrated in Figure 8. The magnitude and profile of the waves are well predicted at all gauge positions except at gauge \# 22. At this point, the model fails to predict the higher harmonics accurately.

The introduction of artificial energy dissipation term not only follows the physical phenomenon of energy dissipation at a steep face of a submerged structure but also leads to stability in numerical computations. However, further studies are necessary in proposing an accurate energy dissipation term eliminating the assumptions made in Ranasinghe et al. (2009). Focus should also be 
given to tuning the dissipation term when the face slope of the submerged breakwater changes from completely vertical to a mild slope, where wave breaking/wave shoaling is expected to occur. Although the slot technique in Madsen et al. (1997) made it possible to simulate the wave transformation over submerged breakwaters with small freeboards, it is not recommended to use the same technique with infinitesimal slot width for submerged breakwaters with the crown being nearly at the still water level.

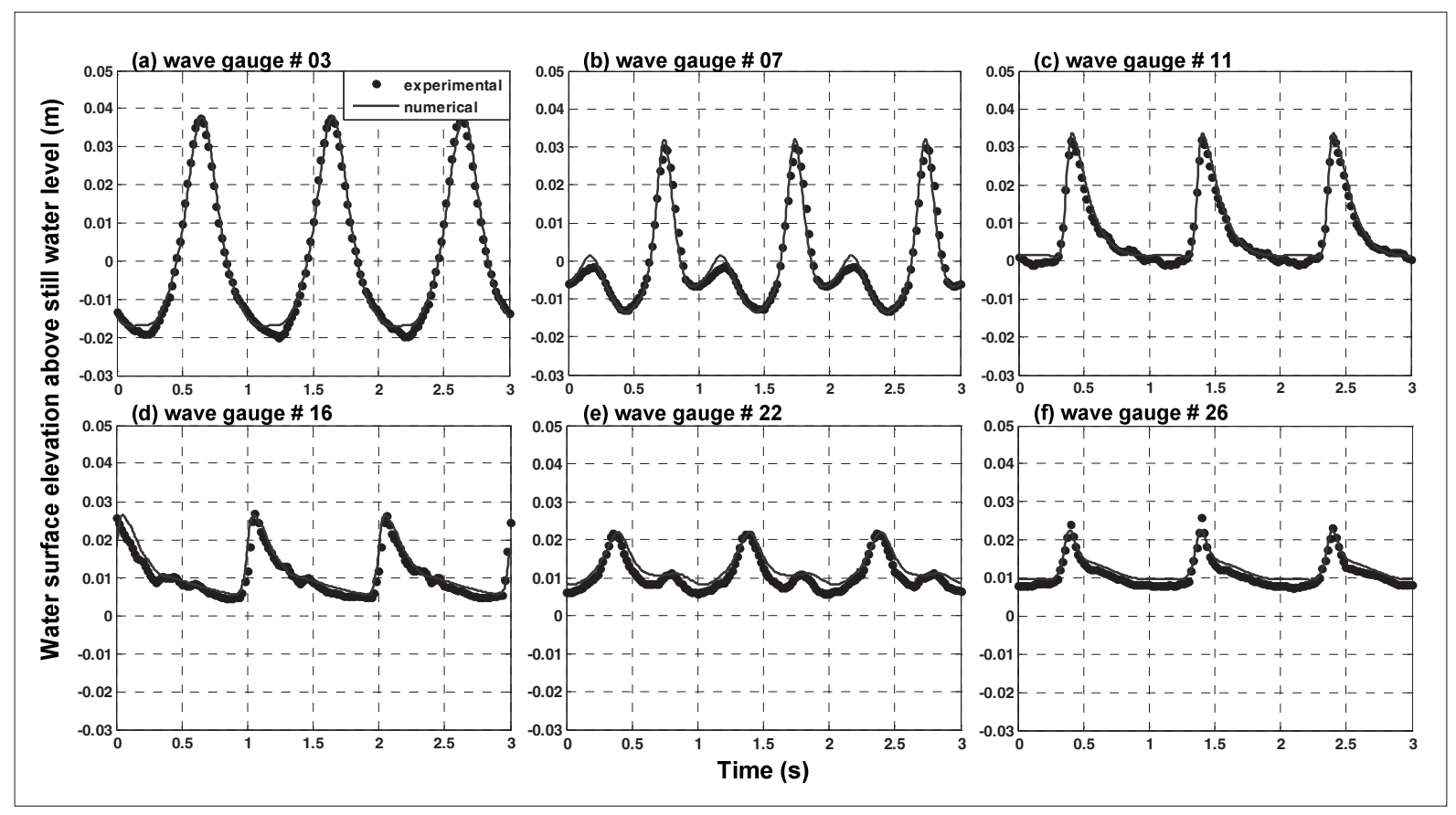

Figure 8: Comparison of instantaneous free water surface elevations simulated using model 1 with measurements at six different wave gauge positions associated with case SB2

\section{CONCLUSION}

Nwogu (1993), and Madsen and Sorensen (1992) Boussinesq-type equations are investigated for stability, when simulating the evolution of nonlinear water waves propagating over submerged breakwaters with relatively steep face slopes and low freeboards, although they are stable and highly capable of simulating waves and currents on mildly sloping beaches (models in original form are inapplicable on steep bottom configurations). Although a number of upgrades with higher order terms and three-dimensional effects have been developed recently to model waves and currents on steep slopes, the models presented in this study are still preferred for practical applications due to better stability and less computational time. The artificial energy dissipation term proposed by Ranasinghe et al. (2009) is successfully introduced into Nwogu (1993) Boussinesq- type equations to suppress unrealistic flow patterns, which tended to occur at the offshoreward face of submerged breakwaters, when the flow is offshoreward (the equivalent energy dissipation term is not introduced to perform numerical simulations with MIKE21 BW as there is no access to the source code). Model simulations are performed for submerged breakwaters with large and small freeboards and the model applicability is verified with a new set of experimental data. However, it is worth further exploring the physics of hydrodynamic processes around submerged breakwaters with steep face slopes and the possibilities of formulating a better energy dissipation term eliminating the assumptions made in Ranasinghe et al. (2009). It is also noted that special treatments are necessary in the numerical model to account for wetting and drying coexisting fields on submerged breakwaters particularly under very small freeboards, as still water depths in Boussinesq-type equations become meaningless during the drying phase. 


\section{Acknowledgement}

The author thank Dr Bjoern Elsasser, Senior Lecturer, School of Planning, Architecture and Civil Engineering, Queen's University of Belfast, United Kingdom for the technical assistance provided on running MIKE21 BW for numerical simulation results.

\section{REFERENCES}

Chen Q., Kirby J.T., Dalrymple R.A., Shi F. \& Thornton E.B. (2003). Boussinesq modeling of longshore currents. Journal of Geophysical Research 108(C11): 3362 - 3378. DOI: https://doi.org/10.1029/2002JC001308

Cruz E.C., Isobe M. \& Watanabe A. (1997). Boussinesq equations for wave transformation on porous beds. Coastal Engineering 30: 125 - 156.

Gironella X. \& Sanchez-Arcilla A. (1999). Hydrodynamic behaviour of submerged breakwaters. Some remarks based on experimental results. Proceedings of the $27^{\text {th }}$ International Conference on Coastal Engineering, Sydney, Australia, pp. $891-896$.

Gobbi M.F., Kirby J.T. \& Wei G. (2000). A fully nonlinear Boussinesq model for surface waves. II. Extension to $O\left(k h^{4}\right)$. Journal of Fluid Mechanics 405: $181-210$. DOI: https://doi.org/10.1017/S0022112099007247

Ishii T., Isobe M. \& Watanabe A. (1994). Improved boundary conditions to a time-dependent mild slope equation for random waves. Proceedings of the $24^{\text {th }}$ International Conference on Coastal Engineering, Kobe, Japan, pp. $272-284$.

Johnson H.K. (2006). Wave modelling in the vicinity of submerged breakwaters. Coastal Engineering 53: $39-48$. DOI: https://doi.org/10.1016/j.coastaleng.2005.09.018

Johnson H.K., Karambas Th.V., Avgeris I., Zanuttigh B., Gonzalez-Marco D. \& Caceres I. (2005). Modelling of waves and currents around submerged breakwaters. Coastal Engineering 52: 949 - 969.

DOI: https://doi.org/10.1016/j.coastaleng.2005.09.011

Karambas Th.V. \& Koutitas C. (2002). Surf and swash zone morphology evolution induced by nonlinear waves. Journal of Waterways, Port, Coastal and Ocean Engineering 128(3): $102-113$.

Kennedy A.B., Chen Q., Kirby J.T. \& Dalrymple R.A. (2000). Boussinesq modelling of wave transformation, breaking and run-up. I:1D. Journal of Waterways, Port, Coastal and Ocean Engineering 126(1): 39 - 47.

Larsen J. \& Dancy H. (1983). Open boundaries in short wave simulations-a new approach. Coastal Engineering 7: $285-297$.

Madsen P.A., Banijamali B., Schaffer H.A. \& Sorensen O.R. (1996). Boussinesq-type equations with high accuracy in dispersion and nonlinearity. Proceedings of the $25^{\text {th }}$ International Conference on Coastal Engineering, Orlando, USA, pp. 95 - 108.

Madsen P.A., Murray R. \& Sorensen O.R. (1991). A new form of the Boussinesq equations with improved linear dispersion characteristics. Coastal Engineering 15: 371 - 388.

Madsen P.A. \& Sorensen O.R. (1992). A new form of the Boussinesq equations with improved linear dispersion characteristics, part 2. A slowly-varying bathymetry. Coastal Engineering 18: 183 - 204.

Madsen P.A., Sorensen O.R. \& Schaffer H.A. (1997). Surf zone dynamics simulated by a Boussinesq type model, part I. Model description and cross-shore motion of regular waves. Coastal Engineering 32: 255 - 287.

Nwogu O.J. (1993). Alternative form of Boussinesq equations for nearshore wave propagation. Journal of Waterways, Port, Coastal and Ocean Engineering 119(6): 618 - 638.

Nwogu O.J. (1996). Numerical prediction of breaking waves and currents with Boussinesq model. Proceedings of the $25^{\text {th }}$ International Conference on Coastal Engineering, Orlando, USA, pp. $4807-4820$.

Ranasinghe R., Larson M. \& Savioli J. (2010). Shoreline response to single shore-parallel submerged breakwater. Coastal Engineering 57: 1006 - 1017.

DOI: https://doi.org/10.1016/j.coastaleng.2010.06.002

Ranasinghe R.S., Sato S. \& Tajima Y. (2009). Boussinesq modelling of waves and currents over submerged breakwaters. Proceedings of the $5^{\text {th }}$ International Conference on Asian and Pacific Coasts, Singapore, volume 3 , pp. $58-64$.

DOI: https://doi.org/10.1142/9789814287951_0097

Schaffer H.A., Madsen P.A. \& Deigaard R. (1993). A Boussinesq model for waves breaking in shallow water. Coastal Engineering 20: 185 - 202.

Vidal C., Lomonaco P., Migoya L., Archetti R., Turchetti M., Sorci M. \& Sassi G. (2002). Laboratory experiments on flow around and inside LCS structures, description of tests and database. DELOS Internal Report, p. 19.

Wei G., Kirby J.T., Grilli S.T. \& Subramanya R. (1995). A fully nonlinear Boussinesq model for surface waves. part 1. Highly nonlinear unsteady waves. Journal of Fluid Mechanics 294: 71 - 92. DOI: https://doi.org/10.1017/S0022112095002813

Zanuttigh B. \& Lamberti A. (2003). Wave basin experiment final form: 3D hydrodynamic tests at Aalborg University, DK. DELOS Project Deliverable D 31, pp. 76. 